\title{
THE FLOW APPROACH FOR WAVES IN NETWORKS
}

\author{
BERND KLÖSS
}

\begin{abstract}
We present a "non-standard method" to treat wave equations on networks, leading to a transport process on the doubled directed graph. From the node conditions, we derive a flow governed by a certain adjacency matrix which, in particular, builds the bridge to the theory of difference operators. This approach provides the fundament for a powerful method to examine (boundary-)controllability and to prove stability results for damped and delay-damped networks of wave equations.
\end{abstract}

Mathematics subject classification (2010): 47B39.

Keywords and phrases: $C_{0}$-semigroups, difference operators, flows in networks.

\section{REFERENCES}

[1] K. Ammari And M. Jellouli, Stabilization of star-shaped networks of strings, Diff. Int. Equ. 17 (2004), 1395-1410.

[2] K. Ammari, M. Jellouli, And M. Khenissi, Stabilization of generic trees of strings, J. Dyn. Control Syst. 11 (2005), 177-193.

[3] F. Ali Mehmeti, Nonlinear waves in networks, Mathematical Research 80 (1994), Akademie-Verlag (Berlin).

[4] F. Ali Mehmeti, J. von Below, and S. Nicaise (eds.), Partial differential equations on multistructures, Lecture Notes in Pure and Applied Mathematics 219 (2001), Marcel Dekker Inc. (New York).

[5] N. Biggs, Algebraic graph theory, Cambridge Mathematical Library (1993), Cambridge University Press (Cambridge).

[6] A. BoricheV AND Y. TOMILOV, Optimal polynomial decay of functions and operator semigroups, Math. Ann. 347 (2010), 455-478.

[7] R. Diestel, Graph theory, Graduate Texts in Mathematics 173 (2005), Springer-Verlag (Berlin).

[8] B. Dorn, M. KRamar FiJavz, R. NAGel, AND A. RadL, The semigroup approach to transport processes in networks, Physica D: Nonlinear Phenomena 239 (2010), 1416-1421.

[9] B. Dorn, V. KeICHER, AND E. SiKolya, Asymptotic periodicity of recurrent flows in infinite networks, Math. Z. 263 (2009), 69-87.

[10] B. Dorn, Semigroups for flows in infinite networks, Semigroup Forum 76 (2008), 341-356.

[11] K.-J. Engel, M. Kramar FijaVvz, R. Nagel, and E. Sikolya, Vertex control of flows in networks, Netw. Heterog. Media 3 (2008), 709-722.

[12] K.-J. Engel, B. Klöss, M. Kramar Fijavvz, R. NAgel, and E. Sikolya, Maximal controllability for boundary control problems, Applied Mathematics and Optimization 62 (2010), 205-227.

[13] K.-J. ENGEL AND R. NAGEL, One-Parameter Semigroups for Linear Evolution Equations, Graduate Texts in Math. 194 (2000), Springer-Verlag (New York).

[14] B.-Z. Guo, Z.-H. Luo, AND O. Morgul, Stability and stabilization of infinite dimensional systems with applications, Communications and Control Engineering Series (1999), Springer-Verlag (London).

[15] M. Kramar Fijavvz, D. Mugnolo, and E. Sikolya, Variational and semigroup methods for waves and diffusion in networks, Appl. Math. Optim. 55 (2007), 219-240.

[16] B. KLÖss, Difference operators as semigroup generators, Semigroup Forum 81 (2010), 461-482.

[17] B. KLÖss, Difference semigroups for vibrating networks, published by Dr.Hut-Verlag, München, 2010. 
[18] M. Kramar And E. Sikolya, Spectral properties and asymptotic periodicity of flows in networks, Math. Z. 249 (2005), 139-162.

[19] G. Leugering, Reverbation analysis and control of networks of elastic strings, Control of partial differential equations and applications, Lecture Notes in Pure and Applied Mathematics 174 (1996), Marcel Dekker Inc. (New York), 193-206.

[20] G. LeUgering, On dynamic domain decomposition of controlled networks of elastic strings and joint-masses, Control and Estimation of Distributed Parameter Systems, Internat. Ser. Numer. Math. 126 (1998), Birkhäuser-Verlag (Basel), 191-205.

[21] G. Leugering, Dynamic domain decomposition of optimal control problems for networks of strings and Timoshenko beams, SIAM J. Control Optim. 37 (1999), 1649-1675.

[22] Y. Le Gorrec, B. MaschKe, J.A. Villegas, AND H. ZWART, Well-posedness and regularity for a class of hyperbolic boundary control systems, 17th International Symposium on Mathematical Theory of Networks and Systems (2006), 1379-1383.

[23] J.E. LAGNESE, G. LeUGERING, AND E.J.P.G. SCHMIDT, Modeling, analysis and control of dynamic elastic multi-link structures, Systems \& Control: Foundations \& Applications (1994), BirkhäuserVerlag (Boston).

[24] G. LeUGERING AND E.J.P.G. SCHMidT, On the control of networks of vibrating strings and beams, Proceedings of the 28th IEEE Conference on Decision and Control 3 (1989), 2287-2290.

[25] T. Mátrai And E. SiKolya, Asymptotic behavior of flows in networks, Forum Math. 19 (2007), 429-461.

[26] S. NiCAise AND J. VAlein, Stabilization of the wave equation on 1-D networks with a delay term in the nodal feedbacks, Netw. Heterog. Media 2 (2007), 425-479.

[27] X.G. QI AND J.J. GUO, The group and Riesz basis properties of string systems with time delay and exact controllability with boundary control, IMA J. Math. Control Inform. 23 (2006), 85-96.

[28] D.L. Russell, Controllability and stabilizability theory for linear partial differential equations: recent progress and open questions, SIAM Rev. 20 (1978), 639-739.

[29] E.J.P.G. SCHMIDT, On the modelling and exact controllability of networks of vibrating strings, SIAM J. Control Optim. 30 (1992), 229-245.

[30] E. SiKolya, Flows in networks with dynamic ramification nodes, J. Evol. Equ. 5 (2005), 441-463.

[31] J. VON BELOW, A characteristic equation associated to an eigenvalue problem on $c^{2}$-networks, Linear Algebra Appl. 71 (1985), 309-325.

[32] J. VON BeLOW, Sturm-Liouville eigenvalue problems on networks, Math. Methods Appl. Sci. 10 (1988), 383-395.

[33] J. vON BeLOw, Kirchhoff laws and diffusion on networks, Lin. Algebra Appl. 121 (1989), 692-697.

[34] J. vON BELOW, Parabolic network equations, Habilitationsschrift, Universität Tübingen, 1993.

[35] J. VON BELOW AND J.A. LubARY, The eigenvalues of the Laplacian on locally finite networks, Results Math. 47 (2005), 199-225.

[36] J. VON BELOW, The eigenvalues of the laplacian on locally finite networks under generalized node transition, Results in Mathematics (2009), 15-39.

[37] J. VAlein AND E. ZUAZUA, Stabilization of the wave equation on 1-D networks, SIAM J. Control Optim. 48 (2009), 2771-2797.

[38] G.-Q. XU AND B.-Z. GuO, Riesz basis property of evolution equations in Hilbert spaces and application to a coupled string equation, SIAM J. Control Optim. 42 (2003), 966-984. 